\title{
Mitomycin C treatment induces resistance and enhanced migration via phosphorylated Akt in aggressive lung cancer cells
}

\author{
Cheng-Ying Shen ${ }^{1, *}$, Li-Han Chen ${ }^{2, *}$, Yu-Fen Lin ${ }^{2,3, *}$, Liang-Chuan Lai ${ }^{4}$, Eric Y. \\ Chuang $2,5,6,7,8,9,10$, Mong-Hsun Tsai ${ }^{1,5,6,7,11}$ \\ ${ }^{1}$ Institute of Biotechnology, National Taiwan University, Taipei, Taiwan \\ ${ }^{2}$ YongLin Biomedical Engineering Center, National Taiwan University, Taipei, Taiwan \\ ${ }^{3}$ Department of Radiation Oncology, University of Texas Southwestern Medical Center, Dallas, Texas, USA \\ ${ }^{4}$ Graduate Institute of Physiology, National Taiwan University, Taipei, Taiwan \\ ${ }^{5}$ Genome and Systems Biology Degree Program, National Taiwan University, Taipei, Taiwan \\ ${ }^{6}$ Bioinformatics and Biostatistics Core, Center of Genomic Medicine, National Taiwan University, Taipei, Taiwan \\ ${ }^{7}$ Center for Biotechnology, National Taiwan University, Taipei, Taiwan \\ ${ }^{8}$ Institute of Epidemiology and Preventive Medicine, National Taiwan University, Taipei, Taiwan \\ ${ }^{9}$ Graduate Institute of Chinese Medical Science, China Medical University, Taichung, Taiwan \\ ${ }^{10}$ Graduate Institute of Biomedical Electronics and Bioinformatics, National Taiwan University, Taipei, Taiwan \\ ${ }^{11}$ Agricultural Biotechnology Research Center, Academia Sinica, Taipei, Taiwan University, Taipei, Taiwan \\ "These authors have contributed equally to this work \\ Correspondence to: Mong-Hsun Tsai, email: motiont@ntu.edu.tw \\ Keywords: CL1-0, CL1-5, cell migration, mitomycin C, phosphorylated AKt \\ Received: August 17, $2016 \quad$ Accepted: October 22, $2016 \quad$ Published: November 09, 2016
}

\section{ABSTRACT}

Since 1984, mitomycin C (MMC) has been applied in the treatment of nonsmall-cell lung cancer (NSCLC). MMC-based chemotherapeutic regimens are still under consideration owing to the efficacy and low cost as compared with other second-line regimens in patients with advanced NSCLC. Hence, it is important to investigate whether MMC induces potential negative effects in NSCLC. Here, we found that the malignant lung cancer cells, CL1-2 and CL1-5, were more resistant to MMC than were the parental CL1-0 cells and pre-malignant CL1-1 cells. CL1-2 and CL1-5 cells consistently showed lower sub-G1 fractions post MMC treatment. DNA repairrelated proteins were not induced more in CL1-5 than in CL1-0 cells, but the levels of endogenous and MMC-induced phosphorylated Akt (p-Akt) were higher in CL1-5 cells. Administering a p-Akt inhibitor reduced the MMC resistance, demonstrating that p-Akt is important in the MMC resistance of CL1-5 cells. Furthermore, we revealed that cell migration was enhanced by MMC but lowered by a p-Akt inhibitor in CL1-5 cells. This study suggests that in CL1-5 cells, the activity of p-Akt, rather than DNA repair mechanisms, may underlie the resistance to MMC and enhance the cells' migration abilities after MMC treatment.

\section{INTRODUCTION}

Lung cancer is the leading cause of cancer-related deaths worldwide [1]. Lung cancer can be categorized into two groups: small-cell lung cancer (SCLC) and NSCLC. NSCLC represents about $85 \%$ of lung cancers
[2]. The 5-year survival rate of patients with lung cancer is lower than that of patients with other kinds of cancer. For patients with early-stage (I and II) lung cancer, the 5 -year survival rate is $54 \%$, while the rate for patients with advanced-stage lung cancer is only $18 \%$ [3]. In the past, surgery was the first option for patients with early stage but not advanced-stage NSCLC [4]. Most patients with 
advanced-stage NSCLC undergo chemotherapy followed by surgery to improve their survival [4].

Mitomycin C (MMC) has been applied in the treatment of NSCLC since 1984 [5]. It has been shown that MMC induces interstrand crosslinks (ICLs) [6], the covalent links between the two strands of DNA, to prevent unwinding of the DNA helix, thus blocking both DNA replication and RNA transcription [7, 8]. Currently, MMC alone is still used as an anti-cancer regimen in cancer patients [9]. However, better survival was demonstrated when MMC was combined with either vinca alkaloid- or platinum-containing drugs in the treatment of patients with advanced-stage NSCLC [10-12]. Moreover, given the efficacy and low cost of MMC and vinorelbine, as compared with other second-line regimens [11], it is likely that MMC-based chemotherapy treatment regimens will be increasingly applied for advanced-stage NSCLC. Unfortunately, even though the initial chemotherapy treatments are successful in advanced-stage NSCLC, the efficacy of MMC-based chemotherapy decreases over time owing to drug resistance in patients with advanced-stage lung cancer [13]. The previous studies showed that DNA repair plays an important role in the development of resistance to chemotherapy drugs in various types of human tumors [14-16]. In addition to DNA repair signalling, the p-Akt plays a key factor in the chemotherapeutic agent-induced resistance in NSCLC [17-19]. Indeed, p-Akt activation is involved in the process of apoptosis inhibition in a variety of human cancer cells [20]. In particular, increased p-Akt expression was associated with stronger chemo-resistance to etoposide, paclitaxel, gemcitabine, cisplatin, trastuzumab [18], and topotecan [21] treatment in NSCLC cell lines. However, neither the importance of DNA repair nor the roles of p-Akt have been explored in advanced lung cancer cells exposed to MMC treatment.

Besides the chemotherapy resistance, metastasis is another major negative characteristic in patients with advanced lung cancer after chemotherapy. One recent study indicated that MMC retarded the migration abilities of human corneal fibroblasts [22] but no study has reported the effects of MMC on lung cancer cells with high metastasis abilities. Thus, four lung adenocarcinoma sublines, namely CL1-0, CL1-1, CL1-2, and CL1-5, which exhibit progressively invasive properties via an in vitro selection process $[23,24]$, are suitable cell models for studying the effects of MMC in lung cancer cells. Among these CL cell lines, CL1-5 cells are the most invasive [23, $25]$ and express higher endogenous expression levels of p-Akt than CL1-0 cells [26]. Moreover, the p-Akt induced via the overexpression of T-LAK Cell-Originated Protein Kinase (TOPK) accompanied by the increased invasion of CL1-0 cells [27] indicated that the activated p-Akt might enhance the cells' migration abilities.

In order to better understand the potential negative effects induced by MMC in NSCLC, in the present study, we performed clonogenic, apoptosis, and cellcycle distribution assays on CL1-0, CL1-1, CL1-2, and CL1-5 cells. Then, we examined several proteins involved in different kinds of DNA repair signalling to determine whether DNA repair mechanisms participate in $\mathrm{MMC}$ resistance. Finally, we applied a p-Akt inhibitor to examine the importance of activated p-Akt in the cell migration and cell proliferation processes of CL1-0 and CL1-5 cells with or without MMC treatment. Through our study, we hope to identify new methods of improving the efficacy of chemotherapy treatments for aggressive cancer.

\section{RESULTS}

\section{CL1-2 and CL1-5 cells were more resistant to MMC than were CL1-0 and CL1-1 cells}

To examine the MMC-induced cytotoxicity, we performed clonogenic assays to analyse the CL1-0, CL11, CL1-2, and CL1-5 cells after exposure to different concentrations of MMC. The results showed that parental CL1-0 and pre-malignant CL1-1 cells were 10-fold more sensitive to treatment with $9 \mu \mathrm{M}$ MMC than were the derivative CL1-2 and CL1-5 cells (Figure 1A). This indicated that CL1-2 and CL1-5 cells were more resistant to MMC than were CL1-0 and CL1-1 cells.

Next, we analysed the sub-G1 fraction for apoptotic cells. After treatment with $3 \mu \mathrm{M} \mathrm{MMC}$, the percentage of sub-G1 fraction was significantly more increased in CL1-0 and CL1-1 cells than it was in CL1-2 and CL1-5 cells at 48 or $72 \mathrm{~h}$ (Figure 1B). In accordance with the results of the sub-G1 assay, cleaved caspase 3 was detected in CL10 and CL1-1 cells but not in CL1-2 and CL1-5 cells at 48 and $72 \mathrm{~h}$ after $3 \mu \mathrm{M}$ MMC treatment (Figure 1C). The results showed that more of the CL1-0 and CL1-1 cells became apoptotic by MMC treatment than did the CL1-2 and CL1-5 cells.

\section{MMC induced longer G2/M arrest in CL1-0 cells}

We selected CL1-0 and CL1-5 cells to further examine the cell cycle distribution after MMC treatment. First, we synchronized CL1-0 and CL1-5 cells using double thymidine treatment (Figure 2A), and then we performed a flow cytometry analysis to determine the cell cycle distribution. After CL1-0 and CL1-5 cells were released from double thymidine synchronization followed by MMC treatment for $1 \mathrm{~h}$, both cell lines were in the $\mathrm{S}$ phase after $2 \mathrm{~h}$ of MMC treatment (Figure 2B). Then, we induced G2/M arrest in both CL1-0 and CL1-5 cells after 6 to $10 \mathrm{~h}$ of MMC treatment. However, more CL1-0 cells, but not CL1-5 cells, were still arrested in the G2/M phase at $14 \mathrm{~h}$ after MMC treatment (Figure 2B). Because longer $\mathrm{G} 2 / \mathrm{M}$ arrest durations were observed in CL1-0 cells after MMC treatment, we further analysed the level of phosphorylated Chk2 (p-Chk2) in CL1-0 and CL1-5 
A

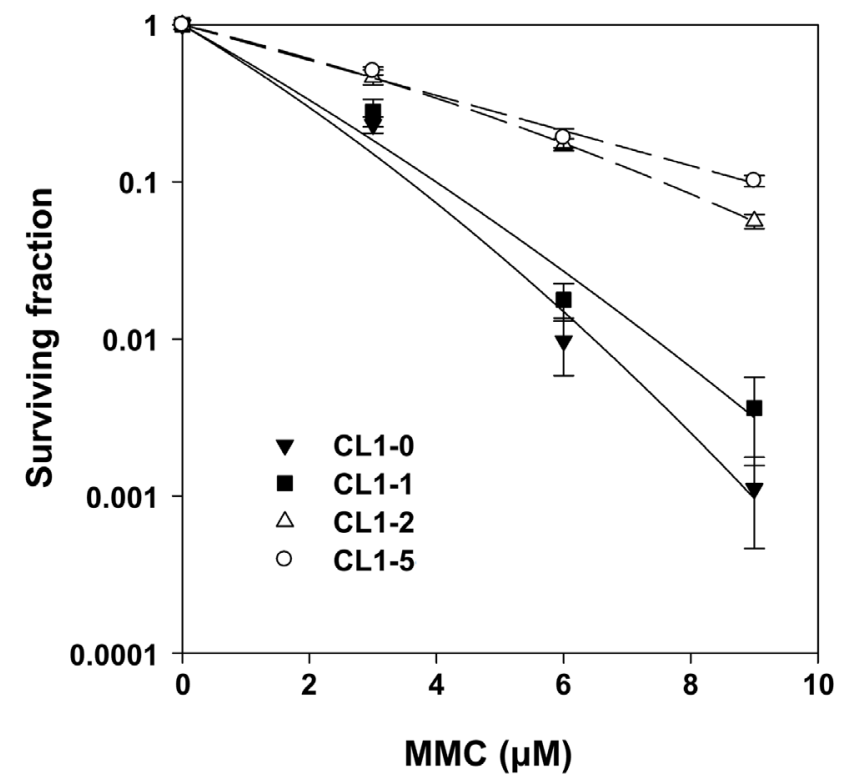

B

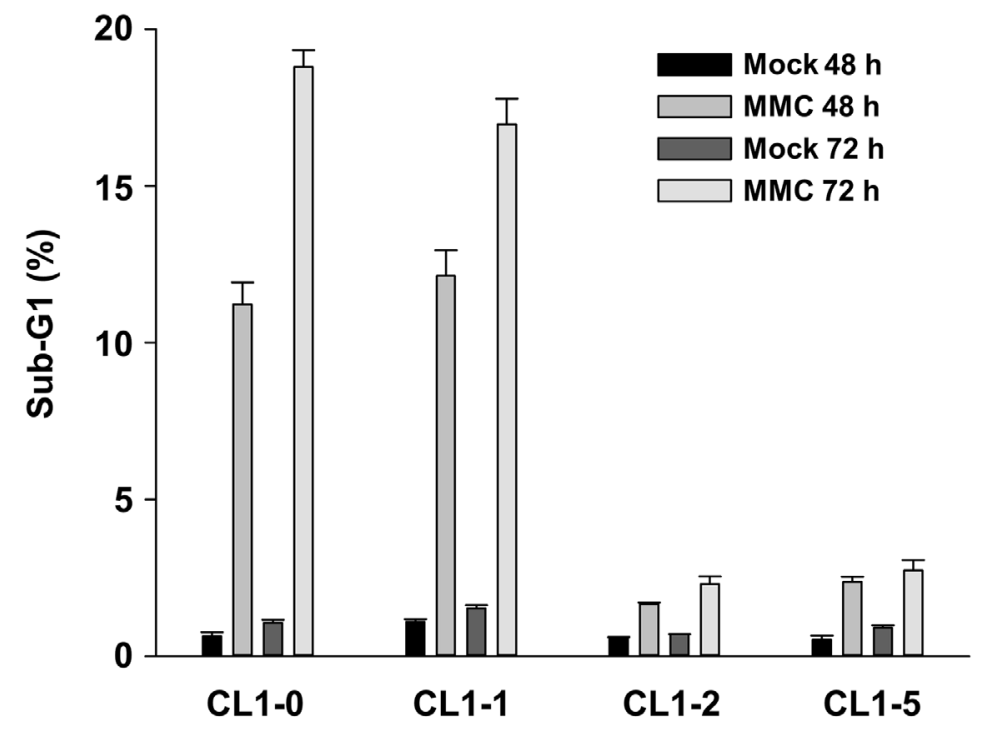

C

\begin{tabular}{|c|c|c|c|c|}
\hline CL1-0 & CL1-1 & CL1-2 & CL1-5 & \\
\hline C 4872 & C 4872 & C 4872 & C 4872 & (h) post MMC ( $3 \mu \mathrm{M}), 1 \mathrm{~h}$ \\
\hline$--\cdots$ & $--\infty$ & $-\infty$ & $--\infty$ & Caspase 3 \\
\hline & $=$ & & & Cleavaged Caspase 3 \\
\hline--1 & --- & --- & --- & Actin \\
\hline
\end{tabular}

Figure 1: The effects of MMC on CL1-0, CL1-1, CL1-2, and CL1-5 cells. A. Colony numbers of CL1-0, CL1-1, CL1-2, and CL1-5 cells at the indicated concentration of MMC treatment $(n=3)$. B. The percent of sub-G1 was measured by propidium iodide staining and flow cytometry following $1 \mathrm{~h}$ treatment with $3 \mu \mathrm{M}$ MMC in CL1-0, CL1-1, CL1-2, and CL1-5 cells $(\mathrm{n}=3)$. C. Immunoblot analysis of full-length and cleaved caspase 3 products in CL1-0, CL1-1, CL1-2, and CL1-5 cells at 48 or $72 \mathrm{~h}$ after $3 \mu \mathrm{M}$ MMC treatment. C: control, cells without MMC treatment. Loading control: actin. 
A

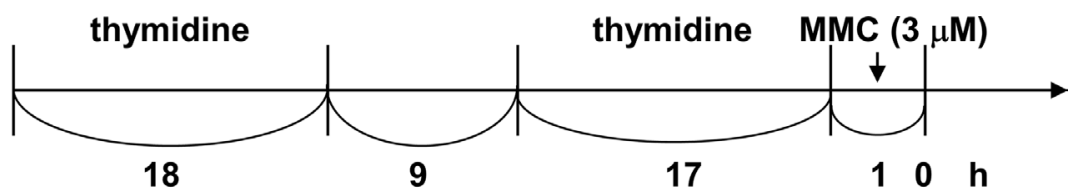

B

CL1-0

CL1-5

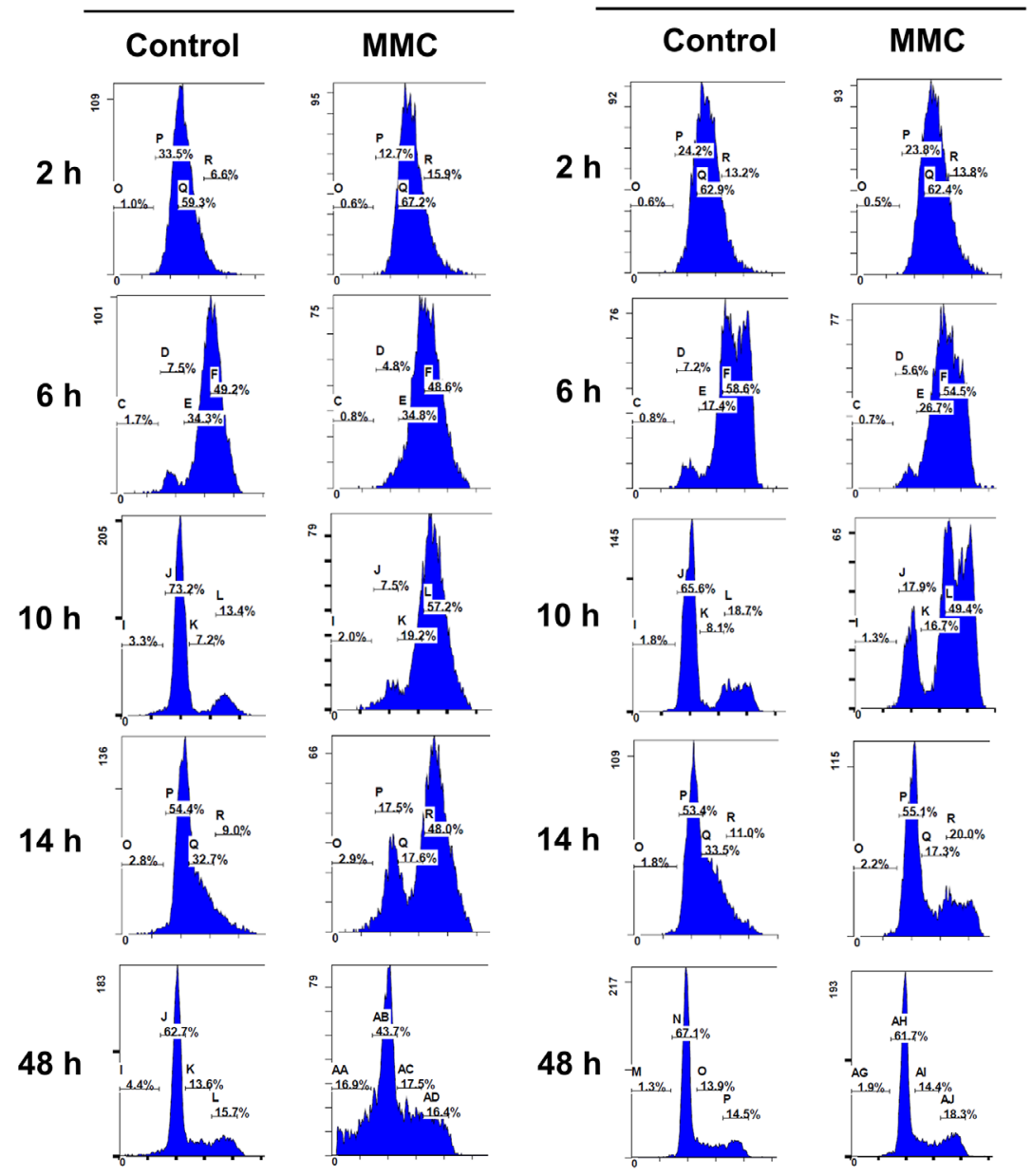

C

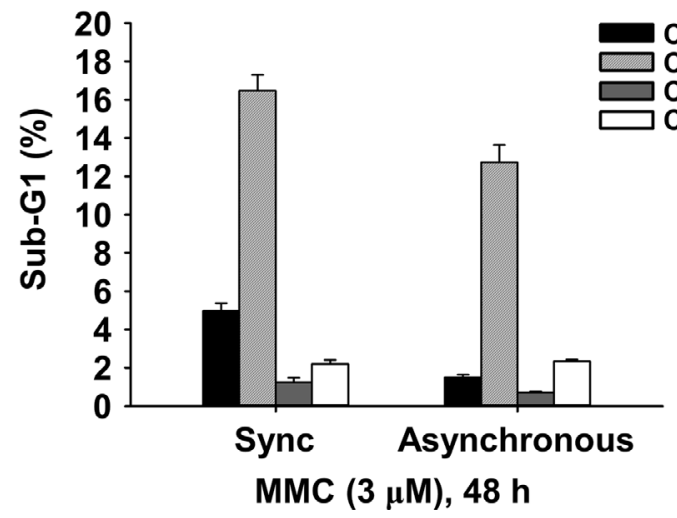

Figure 2: Cell cycle distribution of synchronized CL1-0 and CL1-5 cells post $3 \mu$ M MMC treatment. A. Time scale of double thymidine block and MMC treatment. B. Cell cycle distribution of CL1-0 and CL1-5 cells at the indicated time points post MMC (3 $\mu \mathrm{M})$ treatment in synchronized cells. C. Sub-G1 analysis following $1 \mathrm{~h}$ treatment with $3 \mu \mathrm{M}$ MMC in synchronous or asynchronous CL1-0 and CL1-5 cells $(\mathrm{n}=3)$. 
cells. The results showed that CL1-0 had higher p-Chk2 (T38) activity than did CL1-5 cells at the indicated time points after MMC treatment (Figure S1). Moreover, the percentage of apoptotic cells in the synchronous cells was similar to the percentage in asynchronous cells with or without MMC treatment in CL1-0 and CL1-5 cells at $48 \mathrm{~h}$ (Figure 2C). Therefore, we performed the remaining experiments without double thymidine blocking.

\section{MMC induced Fanconi anaemia and non- homologous end-joining repair signalling in CL1-0 but not CL1-5 cells}

Previous studies indicated that MMC induced DNA interstrand crosslinks to activate several repair pathways such as the nucleotide excision repair (NER), homologous recombination (HR), translesion synthesis (TLS), and Fanconi anaemia (FA) repair pathways [7, 28]. Differences in DNA repair activity may result in the observed differential MMC-induced cytotoxicity between CL1-0 and CL1-5 cells. Moreover, based on our results showing a longer G2/M arrest in CL1-0 than in CL1-5 cells at $14 \mathrm{~h}$, we further studied the activities of DNA repair enzymes within $16 \mathrm{~h}$ after MMC treatment. The results of immunoblot analyses showed that xeroderma pigmentosum, complementation group $\mathrm{C}$ (XPC), and damage-specific DNA binding protein 2 (DDB2) in the NER pathway could not be induced after MMC treatment (Figure 3A). In addition, p-Rad18 (S403) for TLS repair signalling (Figure 3A), as well as p-ATM (S1981) for HR repair signalling (Figure $3 \mathrm{~B}$ ), were activated in both CL1-0 and CL1-5 cells at the indicated time points after treatment with $3 \mu \mathrm{M}$ MMC (Figure 3A). Interestingly, the p-DNA-PKes at S2056 for non-homologous end joining (Figure 3B) and the ubiquitination of Fanconi anaemia complementation group D2 (FANCD2) for FA repair (Figure 3C) showed higher endogenous expression levels and were activated in CL1-0 cells but not in CL15 cells after MMC treatment. We also observed similar expression profiles of FANCD2 and p-ATM (S1981) in CL1-1 and CL1-2 cells (Figure S2). As FANCD2 can bind with other FA proteins to form a complex for repairing DNA interstrand crosslinks [29], we examined the level of FA repair by the number of FANCD2 foci in the nuclei. We found that more FANCD2 nuclear foci were detected in CL1-0 cells than in CL1-5 cells at $24 \mathrm{~h}$ after MMC treatment (Figure 3D). This indicated that more FA repair were activated in CL1-0 cells than in CL1-5 cells at $24 \mathrm{~h}$ after MMC treatment.

\section{Activation of p-Akt in CL1-5 cells reduced the MMC-induced cytotoxicity}

Many studies have indicated that constitutive activation of Akt promotes cell survival and resistance to chemotherapeutic agents $[30,31]$. Hence, we examined the activity of p-Akt in CL1-5 cells with or without MMC treatment. The results showed that the expression levels of total Akt were similar between CL1-0 and CL1-5 cells with or without MMC treatment. However, CL1-5 cells had both a higher level of endogenous p-Akt (S473) and strong activation of $\mathrm{p}$-Akt after MMC treatment compared to CL1-0 cells (Figure 3B). Therefore, we hypothesized that the activation of p-Akt in CL1-5 cells after MMC treatment might play a crucial role against MMC-induced cytotoxicity. To test this hypothesis, we treated cells with a p-Akt inhibitor, MK-2206, which reportedly represses p-Akt levels [32]. The results showed that p-Akt was reduced in MK-2206-treated CL1-0 and CL1-5 cells with or without MMC treatment (Figure 4A). The MK-2206 treatment did not affect cell viability in either the CL10 or CL1-5 cells without MMC (Figure 4B). Moreover, the cell viability of MMC-treated CL1-0 cells was not significantly different between cells that were or were not treated with MK-2206 (Figure 4B). In contrast, MK-2206 significantly decreased the cell viability in MMC-treated CL1-5 cells $(P<0.05)$ (Figure 4B). Likewise, MK-2206 significantly reduced the number of colonies in MMCtreated CL1-5 cells $(P<0.01)$ but not in MMC-treated CL1-0 cells (Figure 4C). These results indicated that p-Akt is important for reducing the cytotoxicity induced by MMC in CL1-5 cells.

\section{MMC increased the migration abilities of CL1-5 but not CL1-0 cells}

CL1-5 cells are more aggressive with higher migration abilities than CL1-0 cells. Therefore, we further analysed the migration abilities of CL1-0 and CL1-5 cells with or without MMC treatment. The results of transwell assays showed that fewer CL1-0 cells migrated through the permeable membrane after MMC treatment $(P<0.05)$ (Figure 5A). In contrast, MMC treatment was able to induce migration in CL1-5 cells (Figure 5A). More importantly, after the level of p-Akt was reduced by MK-2206 in CL1-0 and CL1-5 cells (Figure 5B), the migration abilities of CL1-5 cells but not CL1-0 cells were dramatically decreased (Figure 5A). These results indicated that $\mathrm{MMC}$ could promote migration in the more aggressive CL1-5 cells and that p-Akt may be critical in regulating $\mathrm{MMC}$-induced cell migration.

\section{DISCUSSION}

Chemotherapeutic resistance and metastasis are notable issues in cancer therapy. Furthermore, the previous studies indicated that anticancer- and chemopreventiveagents could induce carcinogenesis or tumor progression [33-35]. MMC, a well-known anticancer drug, was also known as a carcinogen in animal models [36, 37]. The current study provides the first evidence that MMC induces p-Akt, which in turn induces resistance to MMC 
A

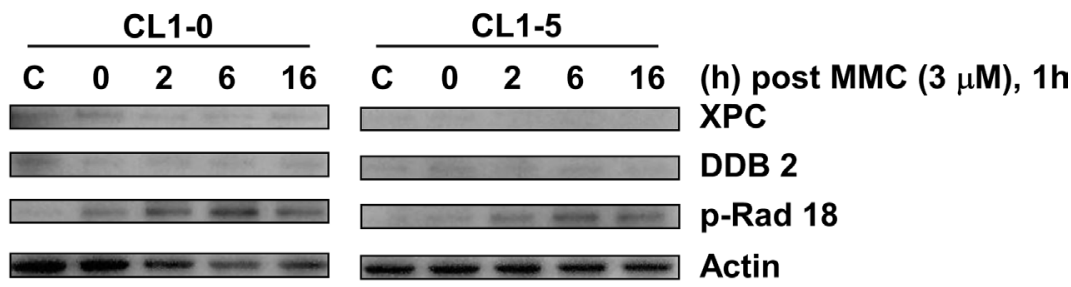

B

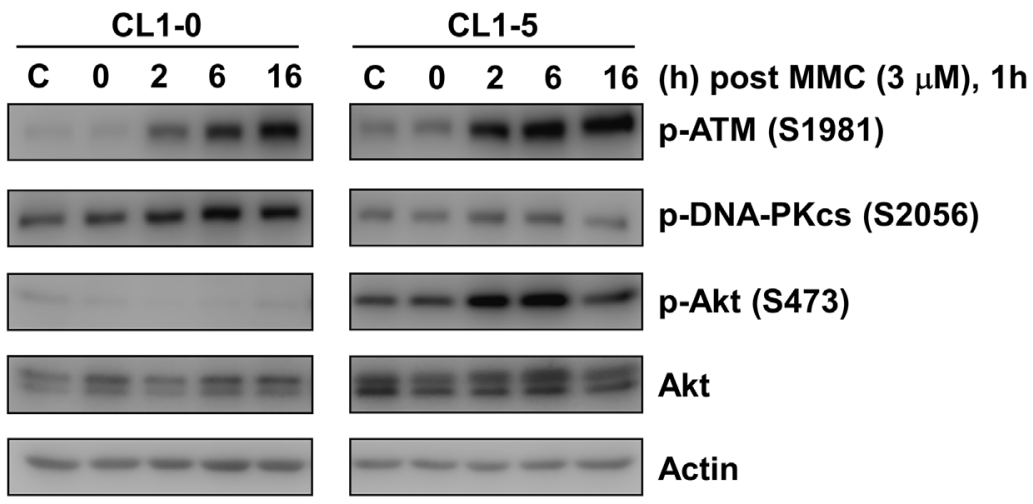

C

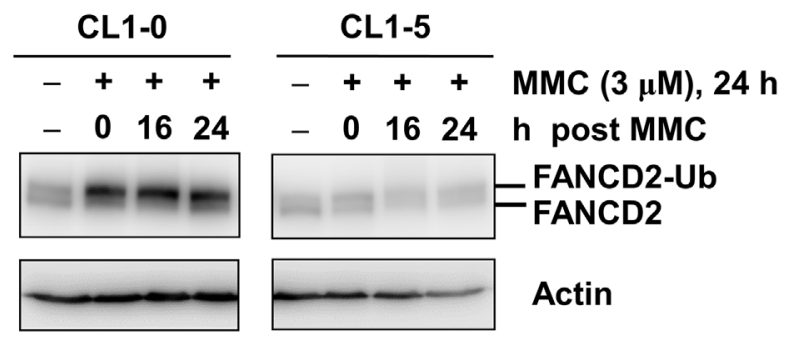

D

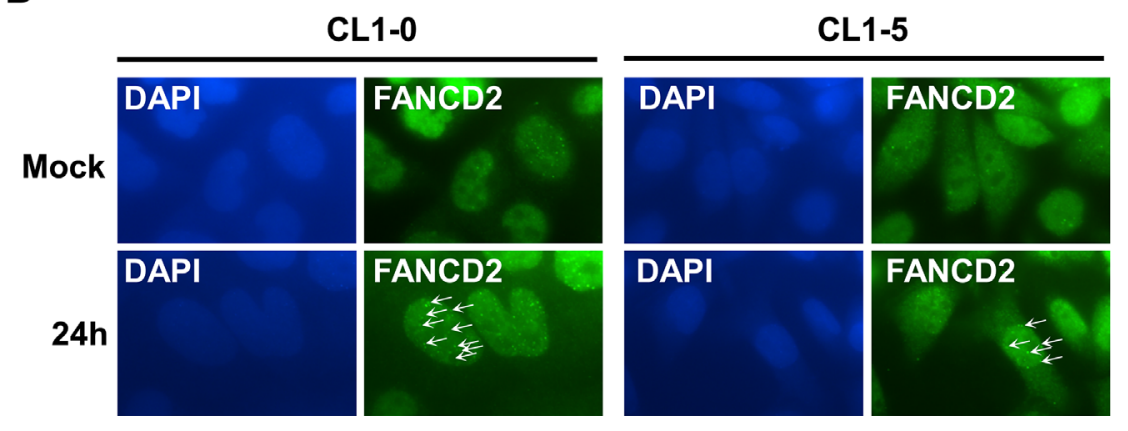

Figure 3: Western blot analysis of DNA damage responses in CI1-0 and CL1-5 cells post $3 \mu \mathrm{MMMC}$ treatment. A. Immunoblot analysis of XPC, DDB2, and p-Rad18 (S403) in CL1-0 and CL1-5 cells at the indicated time points post $3 \mu \mathrm{M}$ MMC treatment. C: control, cells without MMC treatment. Loading control: actin. B. Immunoblot analysis of p-ATM (S1981), p-DNA-PKcs (S2056), p-Akt (S473), and Akt in CL1-0 and CL1-5 cells at different time points post $3 \mu \mathrm{M} \mathrm{MMC} \mathrm{treatment.} \mathrm{C:} \mathrm{control,} \mathrm{cells} \mathrm{without}$ MMC treatment. Loading control: actin. C. Immunoblot analysis of FANCD2 in CL1-0 and CL1-5 cells at the indicated time points post 3 $\mu \mathrm{M}$ MMC treatment.FANCD2-Ub: ubiquitinated FANCD2. Loading control: actin. D. Representative images of CL1-0 or CL1-5 cells with or without $3 \mu \mathrm{M}$ MMC treatment for FANCD2 nuclear foci. Arrows: FANCD2 foci. Green: anti-FANCD2 antibody. Blue: DAPI. 
and enhances the migration abilities of aggressive CL15 cancer cells. The efficiency of DNA repair and the activation of survival signalling are two major mechanisms that correlate the efficacy of chemotherapeutic agents. However, the DNA repair mechanisms that were induced by MMC in CL1-5 cells may not be the main mechanisms underlying $\mathrm{MMC}$ resistance. For instance, we found that the endogenous levels of MMC-induced p-Akt were higher in CL1-5 cells than they were in CL1-0 cells, and we only detected decreased cell viability in CL1-5 cells following p-Akt inhibition. These results indicate that survival signalling, that is $\mathrm{p}$-Akt but not DNA repair signalling, plays a critical role in MMC resistance in CL15 cells. Moreover, we observed that MMC enhanced cell

A

\begin{tabular}{|c|c|c|c|c|c|c|c|c|}
\hline \multicolumn{4}{|c|}{ CL 1-0 } & \multicolumn{4}{|c|}{ CL 1-5 } & \multirow[b]{2}{*}{ MK-2206 } \\
\hline- & + & - & + & - & + & - & + & \\
\hline- & - & + & + & - & - & + & + & MMC \\
\hline 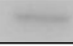 & \multicolumn{3}{|c|}{-} & - & \multicolumn{3}{|c|}{ 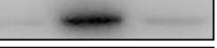 } & p-Akt \\
\hline \multicolumn{4}{|c|}{ 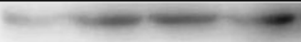 } & \multicolumn{4}{|c|}{ 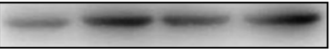 } & Actin \\
\hline
\end{tabular}

B
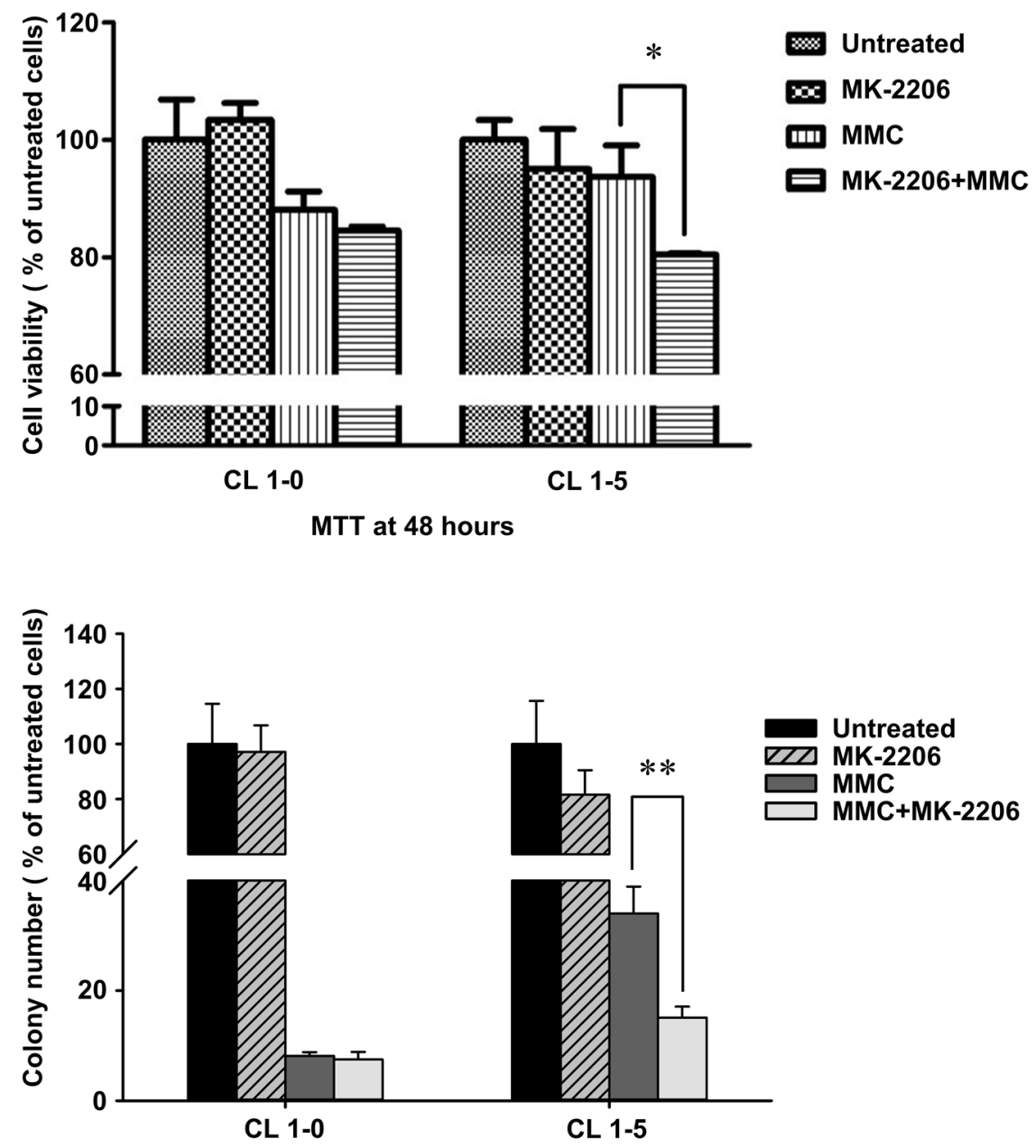

Figure 4: The cell proliferation rates of CL1-0 and CL1-5 cells without p-Akt after MMC treatment. A. The activity of p-Akt was measured by immunoblot analyses in MK-2206-treated or MK-2206-untreated CL1-0 and CL1-5 cells with or without MMC treatment. Loading control: actin. B. The cell proliferation rates of CL1-0 and CL1-5 cells that were untreated, treated with MK-2206, treated with MMC, or treated with a combination of MK-2206 and MMC. $* P<0.05, \mathrm{n}=3$. C. Colony formation of CL1-0 and CL1-5 cells that were untreated, treated with MK-2206, treated with MMC or with a combination of MK-2206 and MMC. $* * P<0.01, \mathrm{n}=4$. All values are represented as mean $+/-\mathrm{SEM}$. 
migration in CL1-5 cells. Since p-Akt increased migration in other types of cells [38-40], it was not surprising that MMC increased the migration abilities of CL1-5 cells via the activation of $\mathrm{p}$-Akt, while the addition of a p-Akt inhibitor reduced these abilities.

Although p-Akt is a key factor involved in the resistance to chemotherapeutic agents including cisplatin $[17,41]$, doxorubicin [41], mitoxantrone [41], paclitaxel [41], etoposide [18], and 5-fluorouracil [41] in NSCLC, the effects of p-Akt on MMC resistance had not been reported before the current study. Kandel et al. revealed that the activities of p-Akt overcame DNA damage induced $\mathrm{G} 2 / \mathrm{M}$ arrest to permit survival and proliferation of cells with accumulated DNA mutations in the surviving cell population [42]. Similarly, CL1-5 not only exhibited the higher endogenous and MMC-induced p-Akt levels but passed G2/M arrest faster than did CL1-0 cells after MMC treatment. Accordingly, the enriched p-Akt was important to allow CL1-5 cells to escape the MMC induced G2/M arrest and may proceed through the cell cycle rapidly without DNA repair mechanisms activation. Therefore, the fast replicated CL1-5 cells may contain high MMC tolerance with accumulated DNA mutations which cannot be detected by FANCD2 foci assay at $24 \mathrm{~h}$ after MMC treatment. In addition, p-Akt could promote cell survival by direct phosphorylation of BAD [43], which dissociated

\section{A}

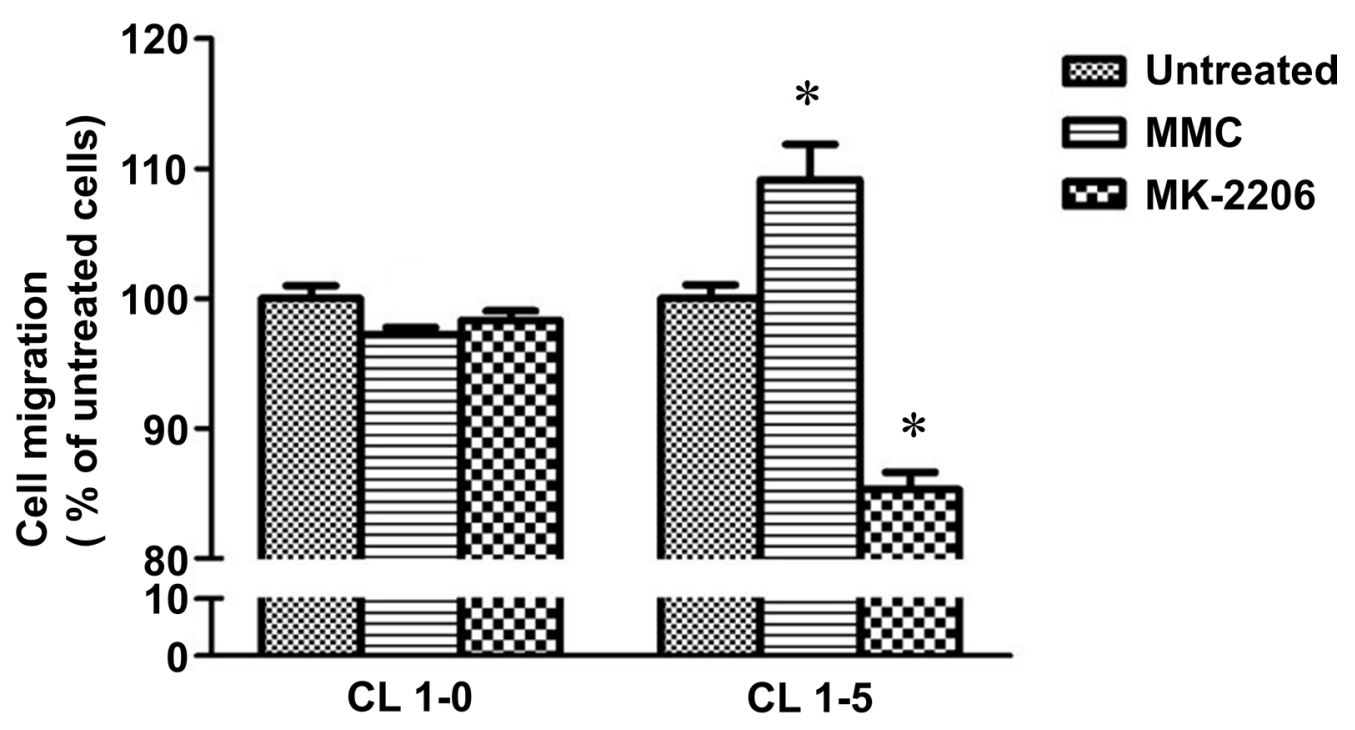

MTT at 48 hours

B

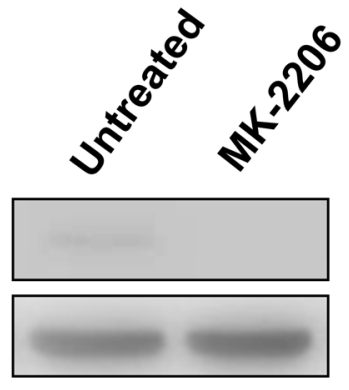

CL 1-0

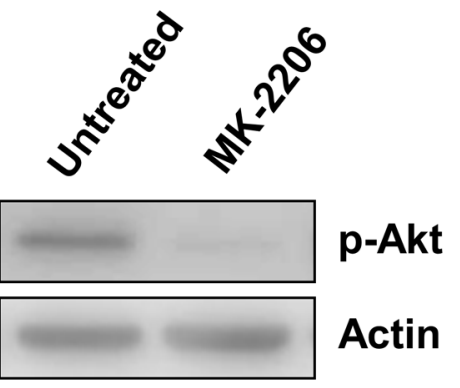

CL 1-5

Figure 5: The migration of CL1-0 and CL1-5 cells without p-Akt after MMC treatment. A. The cell migration of CL1-0 and CL1-5 cells that were untreated, treated with MMC, or treated with MK-2206. $* P<0.05, \mathrm{n}=3$. B. Immunoblot analysis for confirming the decrease in p-Akt by MK-2206 treatment in CL1-0 and CL1-5 cells. Loading control: actin. All values are represented as mean +/- SEM. 
$\mathrm{BAD}$ from the $\mathrm{Bcl}-2 / \mathrm{Bcl}-\mathrm{X}$ complex and lose the BADrelated apoptotic function [44]. Moreover, p-Akt could also trigger survival signalings via activation of NF- $\mathrm{KB}$ related survival genes [45]. Thus, the MMC-induced high level of p-Akt might either inhibit pro-apoptotic proteins or activate pro-survival genes to reduce MMC induced cytotoxicity in CL1-5 cells. Indeed, our results indicate that using p-Akt inhibitors could improve the efficacy of $\mathrm{MMC}$ in lung cancer cells with high endogenous p-Akt expression.

Metastasis is an aggressive feature of cancer $[46,47]$ and it causes $90 \%$ of cancer-related deaths in clinical cases. The previous study also indicated that anticancer drugs treatment can increase further oncogenic characteristics, such as metastasis and invasiveness [48]. Although cisplatin and paclitaxel were linked to metastatic effects via the upregulation of octamer-binding protein 4 , vascular endothelial growth factor receptor 1 , and matrix metalloproteinase 9 [49-51], the effects of MMC on migration in cancer cells had not been reported previously. The phosphoinositide 3-kinase/Akt pathway regulates both the survival and movement of cells [52, 53]. Moreover, the level of $\mathrm{p}$-Akt was found to be much higher in metastatic breast cancer cells than in non-metastatic tumor cells [54]. Therefore, it was reasonable that MMC increased both the level of p-Akt and migration and that the p-Akt inhibitor conversely decreased migration in CL1-5 cells in our study. Our results suggest that MMC-induced p-Akt plays an important role in promoting the migration of CL1-5 cells. We also believe that additional migration signalling pathways may participate in the MMC-induced mechanisms in CL1-0 and CL1-5 cells; however, this requires further study.

To repair chemotherapeutic agent-induced DNA damage, cancer cells can activate the NER, HR, TLS, and FA repair pathways, which cooperate with each other [55]. NER may be defective in CL1-0 and CL1-5 cells owing to the unchanged levels of NER-related proteins, including $\mathrm{XPC}$ and $\mathrm{DDB} 2$, following MMC treatment. This is not surprising because genetic mutations, variations, or silencing of NER pathway-related genes can increase the cancer risk by affecting repair efficacy $[56,57]$. Besides NER, several proteins involved in the HR and TLS signalling pathways were activated in both CL1-0 and CL1-5 cells after MMC treatment. Moreover, MMC induced fewer FA and non-homologous end-joining DNA repair pathway proteins in CL1-5 cells than it did in CL1-0 cells. Since CL1-5 cells did not induce more DNA repair enzyme activity than CL1-0 cells after MMC treatment, the higher resistance of CL1-5 cells to MMC was likely not related to the DNA repair ability. These results suggest that the activated DNA repair mechanisms may not be as important as the expression of p-Akt in the development of resistance to MMC treatment in CL1-5 cells. However, additional studies are needed, because we only examined a few of the DNA repair pathway members in the present study.

In sum, the present study revealed that the level of p-Akt is an important factor underlying MMC resistance and that $\mathrm{MMC}$ seemed to enhance the migration abilities of aggressive CL1-5 cancer cells through the induction of p-Akt. Since cancer metastasis is a negative factor for cancer therapy, treating aggressive cancer with p-Akt-inducing chemotherapeutic agents may need more consideration. Moreover, several studies provided feasibilities for combination of p-Akt inhibitor with other anticancer drugs, such as Erlotinib or Gefitinib, as a viable therapeutic strategy in treating NSCLC [58-60]. Therefore, the present study suggests that the efficacy of chemotherapy may be improved by combining MMC with a p-Akt inhibitor when treating aggressive lung cancer.

\section{MATERIALS AND METHODS}

\section{Cell culture}

Human lung adenocarcinoma cell lines, namely CL1-0, CL1-1, CL1-2, and CL1-5, were cultured in RPMI-1640 medium (ThermoFisher, MA, USA) with 10\% foetal bovine serum (FBS, ThermoFisher) and penicillin and streptomycin $(100 \mathrm{mg} / \mathrm{mL}$ each, ThermoFisher) at $37^{\circ} \mathrm{C}$ in a humidified atmosphere of $5 \% \mathrm{CO} 2$.

\section{MMC treatment and clonogenic assay}

Exponentially growing cells were treated with $\mathrm{MMC}$ at the indicated concentrations for $1 \mathrm{~h}$ at $37^{\circ} \mathrm{C}$. After treatment, variant cell numbers were seeded and cultured for 10 days to yield approximately 30-60 colonies per 60$\mathrm{mm}$ dish (Corning, MO, USA). Colonies were then fixed, stained, and counted. A colony was considered to contain at least 50 cells.

\section{Double thymidine block and flow cytometry analysis}

About $25-30 \%$ confluent cells were cultured in normal medium with $2 \mathrm{mM}$ thymidine for $18 \mathrm{~h}$, then washed with phosphate-buffered saline (PBS) twice, and re-cultured in normal medium for $9 \mathrm{~h}$ followed by an additional incubation with $2 \mathrm{mM}$ thymidine for $17 \mathrm{~h}$. CL1-0 cells and CL1-5 cells were synchronized in G1/S phases with $76-79 \%$ of the population by this point. After the cells were released from the thymidine block, they were harvested at the indicated time points and fixed in $70 \%$ ethanol overnight. Fixed cells were washed with PBS and re-suspended in propidium iodide (PI) solution $(0.1 \mathrm{mg} / \mathrm{mL}$ RNase A, $0.1 \%$ Triton X-100, $20 \mu \mathrm{g} / \mathrm{mL}$ PI in PBS). After incubation in the PI solution for $30 \mathrm{~min}$ at 
room temperature, the DNA content was measured by a FACScan flow cytometer (BD, MA, USA).

\section{Immunoblotting}

Cell pellets were re-suspended and incubated in lysis buffer $(50 \mathrm{mM}$ Tris $7.5,0.4 \mathrm{M} \mathrm{NaCl}, 1 \%$ Tween 20, $1 \%$ NP40, $50 \mathrm{mM}$ sodium orthovanadate, 0.25 M $\beta$-glycerophosphate, $0.5 \mathrm{mM}$ dithiothreitol and protease inhibitors) for $30 \mathrm{~min}$ and then sonicated at $4^{\circ} \mathrm{C}$. The total protein amount was measured by the Bradford method with a protein assay kit (Bio-Rad, CA, USA). Equal amounts of protein from the lysate were loaded and separated by $10 \%$ sodium dodecyl sulphate polyacrylamide gel electrophoresis and transferred onto nitrocellulose membranes (Millipore, CA, USA). The blots were hybridized with primary antibodies against caspase 3 (Millipore), $\beta$-actin (Cell Signaling Technology, MA, USA), XPC (Cell Signaling Technology), DDB2 (Cell Signaling Technology), p-Rad18 (Cell Signaling Technology), p-ATM (S1981) (Cell Signaling Technology), p-Chk2 (T68) (Cell Signaling Technology), p-DNA-PKcs (S2056) (Cell Signaling Technology), p-Akt (S473) (Cell Signaling Technology), and Akt (Cell Signaling Technology), respectively. After incubation with the horseradish peroxidase-conjugated secondary antibodies (Cell Signaling Technology), the horseradish peroxidase activity was detected by an enhanced chemiluminescence system (UVP BioSpectrum Imaging System).

\section{Immunofluorescence staining}

Cells were fixed with $4 \%$ paraformaldehyde in PBS for 15 min, permeabilized with $0.3 \%$ Triton X-100 in PBS for $10 \mathrm{~min}$, and blocked with 5\% normal goat serum in PBS for $1 \mathrm{~h}$ at room temperature. The cells were incubated with primary FANCD2 antibody (Cell Signaling Technology) for $1 \mathrm{~h}$, washed three times with PBS, and then incubated with Alexa Fluor 488Anti- and Texas Red-conjugated secondary antibodies for $1 \mathrm{~h}$ (Invitrogen). Then, cells were washed three times with PBS and mounted in Vectashield mounting medium with 4',6-diamidino-2-phenylindole (Vector Laboratories).

\section{MTT assay}

We seeded $2 \times 10^{4}$ cells on 24 -well plates and harvested the cells daily to measure the cell proliferation. Next, $100 \mu \mathrm{L}$ of $5 \mathrm{mg} / \mathrm{mL}$ (3-(4,5-Dimethylthiazol-2-yl)2,5-diphenyltetrazolium bromide [MTT]; SIGMA) were added to the cells, and the cells were incubated at $37^{\circ} \mathrm{C}$ for $3.5 \mathrm{~h}$. Then, the medium was carefully removed without disturbing the cells. The formed insoluble formazan was dissolved with $400 \mu \mathrm{L}$ of MTT solvent ( $4 \mathrm{mM} \mathrm{HCl}$ mixed with isopropanol), and shaken at room temperature for 15 min. Absorbance was read at $590 \mathrm{~nm}$ by VICTOR multi label plate reader (PerkinElmer, MA, USA).

\section{Transwell assay}

Cells were starved with serum-free medium for 24 h. The 6.5 -mm-diameter cell culture inserts $(8 \mu \mathrm{m}$ pore size, Corning.) were used to perform transwell assays in 24-well plates. We seeded $1 \times 10^{5}$ cells in the upper chamber of the filter in $200 \mu \mathrm{L}$ of FBS-free medium. In the lower chamber, we added $0.75 \mathrm{~mL}$ of complete medium containing 10\% FBS. After $16 \mathrm{~h}$, cells were fixed for 15 min at room temperature with $10 \%$ acetic acid and $10 \%$ methanol, and washed with $1 \times$ PBS. The non-migrating cells on the inner transwell membrane were wiped carefully using a cotton swab and stained with $1 \mathrm{~mL}$ of $0.5 \%$ crystal violet for $30 \mathrm{~min}$, and then washed by water. The stained cells were solubilized with $10 \%$ acetic acid and quantitated on a microplate reader at $580 \mathrm{~nm}$.

\section{Statistical analysis}

Two-tailed Student's $t$-tests were applied to all of the data in this study. Differences were considered to be significant if $P<0.05$. All values in the text and figures are presented as the mean \pm the standard deviation. The sample sizes that we chose are described in the figure legends.

\section{ACKNOWLEDGMENTS}

We thank the Joint Center for Instruments and Research, National Taiwan University, for the assistance with flow cytometry.

\section{CONFLICTS OF INTEREST}

The authors declare no competing financial interests.

\section{GRANT SUPPORT}

This work was supported by Bioinformatics and Biostatistics Core, NTU Center of Genomic Medicine (Excellent Research Projects, 104R8400); and Ministry of Science and Technology, Taiwan (103-2314-B-002-034MY3).

\section{Author contributions}

C.Y.S., L.H.C., and Y.F.L. designed and performed the experiments and wrote the paper; L.C.L. wrote the paper. M.H.T. and E.Y.C. designed the experiments, supervised the project, and wrote the paper. All authors discussed the results and contributed to the manuscript. 


\section{REFERENCES}

1. Siegel R, Ma J, Zou Z, Jemal A. Cancer statistics, 2014. CA Cancer J Clin. 2014; 64:9-29.

2. Landis SH, Murray T, Bolden S, Wingo PA. Cancer statistics, 1999. CA Cancer J Clin. 1999; 49:8-31, 31.

3. DeSantis CE, Lin CC, Mariotto AB, Siegel RL, Stein KD, Kramer JL, Alteri R, Robbins AS, Jemal A. Cancer treatment and survivorship statistics, 2014. CA Cancer J Clin. 2014; 64:252-271.

4. Stathopoulos GP. Five-year survival of nonsmall-cell lung cancer patients after treatment with chemotherapy alone. J Clin Oncol. 1990; 8:565-566.

5. Ruckdeschel JC, Day R, Weissman CH, Stolbach LL, Creech RH. Chemotherapy for metastatic non-small cell bronchogenic carcinoma: cyclophosphamide, doxorubicin, and etoposide versus mitomycin and vinblastine (EST 2575, generation IV). Cancer Treat Rep. 1984; 68:1325-1329.

6. Tomasz M. Mitomycin C: small, fast and deadly (but very selective). Chem Biol. 1995; 2:575-579.

7. Deans AJ, West SC. DNA interstrand crosslink repair and cancer. Nat Rev Cancer. 2011; 11:467-480.

8. Huang Y, Li L. DNA crosslinking damage and cancer - a tale of friend and foe. Translational Cancer Research. 2013; 2:144-154.

9. Zacche MM, Srikrishna S, Cardozo L. Novel targeted bladder drug-delivery systems: a review. Research and reports in urology. 2015; 7:169-178.

10. Lustberg MB, Bekaii-Saab T, Young D, Otterson G, Burak W, Abbas A, McCracken-Bussa B, Lustberg ME, VillalonaCalero MA. Phase II randomized study of two regimens of sequentially administered mitomycin $\mathrm{C}$ and irinotecan in patients with unresectable esophageal and gastroesophageal adenocarcinoma. J Thorac Oncol. 2010; 5:713-718.

11. Babiak A, Hetzel J, Godde F, Konig HH, Pietsch M, Hetzel M. Mitomycin C and Vinorelbine for second-line chemotherapy in NSCLC--a phase II trial. Br J Cancer. 2007; 96:1052-1056.

12. Booton R, Lorigan P, Anderson H, Baka S, Ashcroft L, Nicolson M, O'Brien M, Dunlop D, O'Byrne K, Laurence V, Snee M, Dark G, Thatcher N. A phase III trial of docetaxel/ carboplatin versus mitomycin $\mathrm{C} /$ ifosfamide/cisplatin (MIC) or mitomycin $\mathrm{C} / \mathrm{vinblastine/cisplatin} \mathrm{(MVP)} \mathrm{in} \mathrm{patients}$ with advanced non-small-cell lung cancer: a randomised multicentre trial of the British Thoracic Oncology Group (BTOG1). Ann Oncol. 2006; 17:1111-1119.

13. Seve P, Dumontet C. Chemoresistance in non-small cell lung cancer. Curr Med Chem Anticancer Agents. 2005; 5:73-88.

14. Fojo T. Cancer, DNA repair mechanisms, and resistance to chemotherapy. J Natl Cancer Inst. 2001; 93:1434-1436.

15. Harris AL. DNA repair and resistance to chemotherapy. Cancer Surv. 1985; 4:601-624.
16. Bouwman P, Jonkers J. The effects of deregulated DNA damage signalling on cancer chemotherapy response and resistance. Nat Rev Cancer. 2012; 12:587-598.

17. Liu LZ, Zhou XD, Qian G, Shi X, Fang J, Jiang BH. AKT1 amplification regulates cisplatin resistance in human lung cancer cells through the mammalian target of rapamycin/ p70S6K1 pathway. Cancer Res. 2007; 67:6325-6332.

18. Brognard J, Clark AS, Ni Y, Dennis PA. Akt/protein kinase $\mathrm{B}$ is constitutively active in non-small cell lung cancer cells and promotes cellular survival and resistance to chemotherapy and radiation. Cancer Res. 2001; 61:3986-3997.

19. Toulany M, Rodemann HP. Potential of Akt mediated DNA repair in radioresistance of solid tumors overexpressing erbB-PI3K-Akt pathway. Translational Cancer Research. 2013; 2:190-202.

20. Franke TF, Hornik CP, Segev L, Shostak GA, Sugimoto C. PI3K/Akt and apoptosis: size matters. Oncogene. 2003; 22:8983-8998.

21. Nakashio A, Fujita N, Rokudai S, Sato S, Tsuruo T. Prevention of phosphatidylinositol 3'-kinase-Akt survival signaling pathway during topotecan-induced apoptosis. Cancer Res. 2000; 60:5303-5309.

22. Chen TC, Lai CH, Chang JL, Chang SW. Mitomycin C retardation of corneal fibroblast migration via sustained dephosphorylation of paxillin at tyrosine 118. Invest Ophthalmol Vis Sci. 2012; 53:1539-1547.

23. Chu YW, Yang PC, Yang SC, Shyu YC, Hendrix MJ, $\mathrm{Wu} \mathrm{R}, \mathrm{Wu} \mathrm{CW}$. Selection of invasive and metastatic subpopulations from a human lung adenocarcinoma cell line. Am J Respir Cell Mol Biol. 1997; 17:353-360.

24. Kang Y, Chang Y-Y, Liu Y-C, Lai L-C, Chuang EY, Tsai M-H. A microarray study of radiation-induced transcriptional responses and the role of Jagged 1 in two closely-related lung cancer cell lines. Translational Cancer Research. 2015; 4:314-323.

25. Chu YW, Yang PC, Yang SC, Shyu YC, Hendrix MJ, $\mathrm{Wu} \mathrm{R}, \mathrm{Wu} \mathrm{CW}$. Selection of invasive and metastatic subpopulations from a human lung adenocarcinoma cell line. Am J Respir Cell Mol Biol. 1997; 17:353-360.

26. Tsai HF, Huang CW, Chang HF, Chen JJ, Lee CH, Cheng JY. Evaluation of EGFR and RTK signaling in the electrotaxis of lung adenocarcinoma cells under direct-current electric field stimulation. PLoS One. 2013; 8:e73418.

27. Shih MC, Chen JY, Wu YC, Jan YH, Yang BM, Lu PJ, Cheng HC, Huang MS, Yang CJ, Hsiao M, Lai JM. TOPK/ PBK promotes cell migration via modulation of the PI3K/ PTEN/AKT pathway and is associated with poor prognosis in lung cancer. Oncogene. 2012; 31:2389-2400.

28. Hinz JM. Role of homologous recombination in DNA interstrand crosslink repair. Environ Mol Mutagen. 2010; 51:582-603.

29. Mathew CG. Fanconi anaemia genes and susceptibility to cancer. Oncogene. 2006; 25:5875-5884. 
30. Crowell JA, Steele VE, Fay JR. Targeting the AKT protein kinase for cancer chemoprevention. Mol Cancer Ther. 2007; 6:2139-2148

31. Sheppard K, Kinross KM, Solomon B, Pearson RB, Phillips WA. Targeting PI3 kinase/AKT/mTOR signaling in cancer. Crit Rev Oncog. 2012; 17:69-95.

32. Hirai H, Sootome H, Nakatsuru Y, Miyama K, Taguchi S, Tsujioka K, Ueno Y, Hatch H, Majumder PK, Pan BS, Kotani H. MK-2206, an allosteric Akt inhibitor, enhances antitumor efficacy by standard chemotherapeutic agents or molecular targeted drugs in vitro and in vivo. Mol Cancer Ther. 2010; 9:1956-1967.

33. Blagosklonny MV. Antiangiogenic therapy and tumor progression. Cancer Cell. 2004; 5:13-17.

34. Blagosklonny MV. Carcinogenesis, cancer therapy and chemoprevention. Cell Death Differ. 2005; 12:592-602.

35. Blagosklonny MV. How Avastin potentiates chemotherapeutic drugs: action and reaction in antiangiogenic therapy. Cancer Biol Ther. 2005; 4:1307-1310.

36. Mitomycin C. IARC Monogr Eval Carcinog Risk Chem Man. 1976; 10:171-179.

37. Overall evaluations of carcinogenicity: an updating of IARC Monographs volumes 1 to 42. IARC Monogr Eval Carcinog Risks Hum Suppl. 1987; 7:1-440.

38. Buitenhuis $\mathrm{M}$. The role of $\mathrm{PI} 3 \mathrm{~K} /$ protein kinase $\mathrm{B}(\mathrm{PKB} / \mathrm{c}-$ akt) in migration and homing of hematopoietic stem and progenitor cells. Curr Opin Hematol. 2011; 18:226-230.

39. Zhou GL, Tucker DF, Bae SS, Bhatheja K, Birnbaum MJ, Field J. Opposing roles for Akt1 and Akt2 in Rac/ Pak signaling and cell migration. J Biol Chem. 2006; 281:36443-36453.

40. Liao J, Planchon SM, Wolfman JC, Wolfman A. Growth factor-dependent AKT activation and cell migration requires the function of $\mathrm{c}-\mathrm{K}(\mathrm{B})$-Ras versus other cellular ras isoforms. J Biol Chem. 2006; 281:29730-29738.

41. Hovelmann S, Beckers TL, Schmidt M. Molecular alterations in apoptotic pathways after $\mathrm{PKB} / \mathrm{Akt}$-mediated chemoresistance in NCI H460 cells. Br J Cancer. 2004; 90:2370-2377.

42. Kandel ES, Skeen J, Majewski N, Di Cristofano A, Pandolfi PP, Feliciano CS, Gartel A, Hay N. Activation of Akt/protein kinase B overcomes a $\mathrm{G}(2) / \mathrm{m}$ cell cycle checkpoint induced by DNA damage. Mol Cell Biol. 2002; 22:7831-7841.

43. Datta SR, Dudek H, Tao X, Masters S, Fu H, Gotoh Y, Greenberg ME. Akt phosphorylation of BAD couples survival signals to the cell-intrinsic death machinery. Cell. 1997; 91:231-241.

44. Downward J. How BAD phosphorylation is good for survival. Nat Cell Biol. 1999; 1:E33-35.

45. Bai D, Ueno L, Vogt PK. Akt-mediated regulation of NFkappaB and the essentialness of NFkappaB for the oncogenicity of PI3K and Akt. Int J Cancer. 2009; 125:2863-2870.
46. Hanahan D, Weinberg RA. Hallmarks of cancer: the next generation. cell. 2011; 144:646-674.

47. Gužvić M, Klein CA. Towards prevention of metastatic prostate cancer: recent molecular insights from the direct analysis of metastatic precursor cells. Translational Cancer Research. 2016:S182-S186.

48. Liang Y, O'Driscoll L, McDonnell S, Doolan P, Oglesby I, Duffy K, O'Connor R, Clynes M. Enhanced in vitro invasiveness and drug resistance with altered gene expression patterns in a human lung carcinoma cell line after pulse selection with anticancer drugs. Int J Cancer. 2004; 111:484-493.

49. Gingis-Velitski S, Loven D, Benayoun L, Munster M, Bril R, Voloshin T, Alishekevitz D, Bertolini F, Shaked Y. Host response to short-term, single-agent chemotherapy induces matrix metalloproteinase-9 expression and accelerates metastasis in mice. Cancer Res. 2011; 71:6986-6996.

50. Daenen LG, Roodhart JM, van AM, Dehnad M, Roessingh W, Ulfman LH, Derksen PW, Voest EE. Chemotherapy enhances metastasis formation via VEGFR-1-expressing endothelial cells. Cancer Res. 2011; 71:6976-6985.

51. Tang YA, Chen CH, Sun HS, Cheng CP, Tseng VS, Hsu HS, Su WC, Lai WW, Wang YC. Global Oct4 target gene analysis reveals novel downstream PTEN and TNC genes required for drug-resistance and metastasis in lung cancer. Nucleic acids research. 2015; 43:1593-1608.

52. Katso R, Okkenhaug K, Ahmadi K, White S, Timms J, Waterfield MD. Cellular function of phosphoinositide 3-kinases: implications for development, homeostasis, and cancer. Annu Rev Cell Dev Biol. 2001; 17:615-675.

53. Musa F, Schneider R. Targeting the PI3K/AKT/mTOR pathway in ovarian cancer. Translational Cancer Research. 2015; 4:97-106.

54. Qiao M, Iglehart JD, Pardee AB. Metastatic potential of 21T human breast cancer cells depends on Akt/protein kinase B activation. Cancer Res. 2007; 67:5293-5299.

55. Moldovan GL, D'Andrea AD. How the fanconi anemia pathway guards the genome. Annu Rev Genet. 2009; 43:223-249.

56. Sakoda LC, Loomis MM, Doherty JA, Julianto L, Barnett MJ, Neuhouser ML, Thornquist MD, Weiss NS, Goodman GE, Chen C. Germ line variation in nucleotide excision repair genes and lung cancer risk in smokers. International journal of molecular epidemiology and genetics. 2012; $3: 1-17$.

57. Hou SM, Falt S, Angelini S, Yang K, Nyberg F, Lambert B, Hemminki K. The XPD variant alleles are associated with increased aromatic DNA adduct level and lung cancer risk. Carcinogenesis. 2002; 23:599-603.

58. Lara PN, Jr., Longmate J, Mack PC, Kelly K, Socinski MA, Salgia R, Gitlitz B, Li T, Koczywas M, Reckamp KL, Gandara DR. Phase II Study of the AKT Inhibitor MK-2206 plus Erlotinib in Patients with Advanced Non-Small Cell 
Lung Cancer Who Previously Progressed on Erlotinib. Clin Cancer Res. 2015; 21:4321-4326.

59. Papadimitrakopoulou V, Lee JJ, Wistuba, II, Tsao AS, Fossella FV, Kalhor N, Gupta S, Byers LA, Izzo JG, Gettinger SN, Goldberg SB, Tang X, Miller VA, Skoulidis F, Gibbons DL, Shen L, et al. The BATTLE-2 Study: A Biomarker-Integrated Targeted Therapy Study in Previously Treated Patients With Advanced Non-Small-Cell Lung Cancer. J Clin Oncol. 2016.
60. Cheng Y, Zhang Y, Zhang L, Ren X, Huber-Keener KJ, Liu X, Zhou L, Liao J, Keihack H, Yan L, Rubin E, Yang JM. MK-2206, a novel allosteric inhibitor of Akt, synergizes with gefitinib against malignant glioma via modulating both autophagy and apoptosis. Mol Cancer Ther. 2012; 11:154-164. 